\title{
Volume Density, Distribution, and Ultrastructure of Secretory and Basolateral Membranes and Mitochondria Predict Parietal Cell Secretory (Dys)function
}

\author{
Marian L. Miller, ${ }^{1}$ Anastasia Andringa,, ${ }^{1}$ ana Zavros, ${ }^{2}$ Emily M. Bradford, ${ }^{3}$ \\ and Gary E. Shull ${ }^{3}$ \\ ${ }^{1}$ Department of Environmental Health, University of Cincinnati, 3223 Eden Avenue, Cincinnati, OH 45267, USA \\ ${ }^{2}$ Department of Molecular and Cellular Physiology, University of Cincinnati, 231 Albert Sabin Way, \\ Cincinnati, OH 45267-0576, USA \\ ${ }^{3}$ Department of Molecular Genetics, Biochemistry and Microbiology, University of Cincinnati, 231 Albert Sabin Way, \\ Cincinnati, OH 45267-0524, USA
}

Correspondence should be addressed to Marian L. Miller, millermn@ucmail.uc.edu

Received 21 July 2009; Revised 3 November 2009; Accepted 7 December 2009

Academic Editor: Karl Chai

Copyright ( $) 2010$ Marian L. Miller et al. This is an open access article distributed under the Creative Commons Attribution License, which permits unrestricted use, distribution, and reproduction in any medium, provided the original work is properly cited.

Acid secretion in gastric parietal cells requires highly coordinated membrane transport and vesicle trafficking. Histologically, consensus defines acid secretion as the ratio of the volume density (Vd) of canalicular and apical membranes (CAMs) to tubulovesicular (TV) membranes, a value which varies widely under normal conditions. Examination of numerous achlorhydric mice made it clear that this paradigm is discrepant when used to assess most mice with genetic mutations affecting acid secretion. $\mathrm{Vd}$ of organelles in parietal cells of 6 genetically engineered mouse strains was obtained to identify a stable histological phenotype of acid secretion. We confirmed that CAM to TV ratio fairly represented secretory activity in untreated and secretion-inhibited wild-type (WT) mice and in NHE2-/- mice as well, though the response was significantly attenuated in the latter. However, high CAM to TV ratios wrongly posed as active acid secretion in AE2-/-, GHKA $\alpha-/-$, and NHE4-/- mice. Achlorhydric genotypes also had a significantly higher Vd of basolateral membrane than WT mice, and reduced Vd of mitochondria and canaliculi. The $\mathrm{Vd}$ of mitochondria, and ratio of the $\mathrm{Vd}$ of basolateral membranes/ $\mathrm{Vd}$ of mitochondria were preferred predictors of the level of acid secretion. Alterations in acid secretion, then, cause significant changes not only in the Vd of secretory membranes but also in mitochondria and basolateral membranes.

\section{Introduction}

Gastric acid secretion is regulated by paracrine, endocrine, and neural stimuli [1-7]. This involves translocating/collating essential proteins to appropriate cytoplasmic and membrane sites, vesicle trafficking, membrane docking, fusion and fission [8-10], modulation of mitochondrial activities, and the coordinated regulation of ion transport proteins, as well as coupling of cytoskeletal proteins to the canalicular membrane via intermediate linking. Equitable and sustainable energy and ion transport, coordinated in all parts of the cell, is needed to maintain cell homeostasis and successful acid secretion, ultimately affecting and defining parietal cell morphology [11-13].

Ultrastructurally, there is long-standing historical precedence for equating secretory activity with the relative volume densities (Vds) of canalicular and apical membranes (CAMs) and tubulovesicular membranes (TV). The modulation of these membranes has served as an indicator of quiescent and active secretion, which was established early-on with rigorous morphometry $[1,3,8,14-19]$. A paucity of TV was equated with hyperstimulation of parietal cell, and inhibition of acid secretion with a cytoplasm containing mostly tubulovesicles. Similar quantitative evaluations of 
membranes and other organelles in genetically engineered achlorhydric mouse models are much less common [2023], and since results from these models are inconsistent, the debate continues over the relationship between TV and CAM.

The purpose of this study was to correlate parietal cell ultrastructure with the reported level of acid secretion in several mouse models of achlorhydria, in order to define a more reliable phenotype. Brief descriptions of the normo-, hypo-, and achlorhydric mouse models used in this study are as follows:

The AE2 $\mathrm{Cl}^{-} / \mathrm{HCO}_{3}^{-}$exchanger (anion exchanger 2, Slc4a2) is expressed in most cell types at low levels but is highly expressed on the basolateral membranes of parietal cells, $[11,24,25]$ where it mediates chloride and bicarbonate exchange required for $\mathrm{HCl}$ secretion and participates in the maintenance of cell volume and intracellular $\mathrm{pH}[26$, 27]. The loss of AE2 produced achlorhydria but did not have a major effect on parietal cell viability [11]. The Vd of secretory canaliculi and of TV was severely reduced, basolateral membrane infoldings were increased, and the gastric gland lumens were filled with electron dense debris. Canalicular and apical microvillar membranes appeared to be normal morphologically.

The gastric $\mathrm{H}^{+}, \mathrm{K}^{+}$, ATPase alpha subunit (GHKA $\alpha$, Atp4a) is abundantly expressed in parietal cells and its loss produces achlorhydria. The alpha subunit contains the ATP and cation binding sites required for the export of $\mathrm{H}^{+}$from the apical microvilli into the gastric gland lumen. GHKA $\alpha$ appears to interact directly with cytoskeletal proteins and, as such, may actively participate in the modulation of TV and CAM during stimulation [28]. Numerous and severe ultrastructural abnormalities including dilated canalicular spaces, abnormal microvilli, absence of and/or replacement of TV with round vesicles, abnormally large mitochondria with whorled cristi, the accumulation of parietal cell glycogen, and epithelial metaplasia accompanied the loss of GHKA $\alpha$ [29].

The NHE2 $\mathrm{Na}^{+} / \mathrm{H}^{+}$exchanger (Slc9a2) has not yet been localized within the parietal cell [30]. Although it may be localized to basolateral membranes, it is expressed on apical membranes in other cell types [31,32]. NHE2-/- mice are hypochlorhydric initially, the amount of gastric acid measured in stomach progressively declines, and parietal cell viability is very much decreased [30]. Parietal cell ultrastructure showed mostly normal looking CAM and TV and mitochondria.

The NHE4 $\mathrm{Na}^{+} / \mathrm{H}^{+}$exchanger (Slc9a4), required for acid secretion, is also abundant in parietal cells [25] and is expressed on basolateral membranes [12,33]. NHE4-/mice are severely hypochlorhydric, have compromised parietal cell development or viability, and show a greatly reduced Vd of both CAM and TV. CAMs are normal-looking but the cytoplasm just adjacent to the microvilli is mostly devoid of mitochondria and vesicles of any type [12] (a site where both are usually present in WT). CAMs almost exclusively appeared as shallow invaginations from the apical membrane, rather than deep canalicular nidi.

Morphology of the double null mice (NHE2-/-AE2-/and NHE2-I- GHKA $\alpha \alpha-/-$ ) has not been reported in detail previously, but parietal cells appeared to default to the characteristics of the AE2-/- and GHKA $\alpha-/-$ mice, respectively, with some uniqueness in each.

Normochlorhydric knockout (KO) mouse strains used as controls included those for the NHE1 (Slc9a1) and NHE3 (Slc9a3) $\mathrm{Na}^{+} / \mathrm{H}^{+}$exchangers, the NKCC1 (Slc12a2) $\mathrm{Na}^{+}-\mathrm{K}^{+}-$ $2 \mathrm{Cl}^{-}$cotransporter, and the PMCA4 (Atp2b4) plasma membrane $\mathrm{Ca}_{2}{ }^{+}$-ATPase. These $\mathrm{KO}$ mice, and their parietal cells have also been described previously, and were determined in this study, by morphometry, not to be significantly different from parietal cells in wild-type (WT) mice [34-37].

Our aim was to identify parietal cell phenotypes which predictably reflected the level of acid secretion reported for the $\mathrm{pH}$ of gastric contents. It was concluded that of the numerous morphometric parameters that we measured, the $\mathrm{Vd}$ of mitochondria (alone), the Vd of all secretory membranes (together), and the $\mathrm{Vd}$ of basolateral membranes/Vd of mitochondria were good predictors of parietal cell activity. The latter two were less influenced by the structural defects in the $\mathrm{KO}$ mice which compromised modulation of TV and CAM.

\section{Materials and Methods}

2.1. Animals. WT mice plus 4 strains of normochlorhydric mice (NHE1-/-, NHE3-/-, NKCC1-/-, PMCA4-/-) were used as controls. Two hypochlorhydric/achlorhydric mouse lines (NHE2-/- and NHE4-/-) and 4 strains of achlorhydric mice (single knockouts, AE2-/-, GHKA $\alpha-/-$, and both NHE2-/-AE2-/ - and NHE2-/- GHKA $\alpha-/-$ double knockouts) were used experimentally.

All mice were housed in humidity and temperature controlled rooms, on a 12-hour light/dark cycle, with access to standard mouse chow and water ad libitum, except when fasted. Gender- and age-matched WT mice were paired with all KOs. AE2-1- mice and their matched WT pairs were usually under three weeks old, because of early mortality in the former [11]. All other mice varied from 3 weeks to over 1 year old at euthanasia, with approximately equal numbers of males and females in those pairs. Animal protocols were approved by the University of Cincinnati Institutional Animal Care and Use Committee and animal handlers were trained in an American Association of Assessment and Accreditation of Laboratory Animal Care facility. Mice were cared for, and inspected daily.

Acid secretion, in WT and NHE2-/- mice only, was inhibited by fasting, omeprazole treatment $(200 \mu$ moles $/ \mathrm{kg}$ orally two times per day for 2 weeks) or, vagotomy. Fasting included withholding food from mice housed in wire cages with no bedding for 12 hours prior to euthanasia. Paired WT and NHE2-I- mice were surgically vagotomized (Charles River Laboratory) when animals were approximately 5 months of age. After three additional months (180 to 220 days) mice were euthanized. Hyperchlorhydria was induced in WT mice using histamine (Sigma), at a subcutaneous dose of $2 \mu \mathrm{g} / \mathrm{gram}$ body weight in phosphate buffered saline and animals were euthanized after either 15 or 20 minutes. 
2.2. Tissue Processing. Euthanasia was effected with carbon dioxide followed by cutting the diaphragm. The stomach was dissected immediately, opened along the greater curvature, rinsed free of food in phosphate buffered saline (PBS), and fixed by immersion in $2 \%$ paraformaldehyde $/ 2.5 \%$ glutaraldehyde in PBS or in 4\% paraformaldehyde in PBS for at least 24 hours. All tissue blocks were postfixed in $1 \%$ osmium tetroxide in either Millonig's buffer or PBS for 2 hours, dehydrated stepwise in increasing concentrations of ethanol, two changes of propylene oxide, and in one change each of $1: 1$ and $1: 3$ propylene oxide:SpurrR (Electron Microscopy Sciences, Hatfield PA). Tissues were left overnight in fresh $100 \%$ resin and embedded in BeemR capsules (Electron Microscopy Sciences, Hatfield PA) the following day in fresh resin with tissue oriented so that epithelium could be cut perpendicularly to the plane of the basement membrane. Sections were cut at 1.5 to 2 microns thick and stained with toluidine blue for light microscopy. Tissue was also preserved in formalin, dehydrated in ethanol and xylene, blocked in paraffin, sectioned at 5 microns, and stained with hematoxylin and eosin (H\&E).

Thin (gold) plastic sections were stained with uranyl acetate and lead citrate for transmission electron microscopy.

\subsection{Microscopy and Morphometry. The total number of mice} used in this study was 116 . The number of KO, double$\mathrm{KO}$, and WT mice per group varied from 2 to 46 . The number $(n)$ of mice in any given analysis was included within the bar graphs. The 4 normochlorhydric KO genotypes and 4 normochlorhydric heterozygous mice from among these genotypes were pooled with WT mice, since no significant differences were found in morphometry compared to WT.

Electron micrographs of parietal cells for morphometry were taken as they were sequentially encountered at the microscope, avoiding operator bias in the selection of individual cells. Parietal cells in the mucus pit region of the gastric epithelium were excluded; however, the parietal cells included in the dataset represented a summary of those from the gastric gland neck and basal regions.

A grid of 285 points was overlaid onto micrographs of parietal cells. Intersections of the grid which fell over the following cytoplasmic and nuclear events were counted: (1) basal and lateral membranes (BLM), (2) round vesicles (RV), (3) tubulovesicles (TV) (distinctly oval or tubular or irregularly shaped), (4) canalicular and apical microvillar membranes (CAM), (5) apical membrane without characteristic microvilli (as in the case of the GHKA $\alpha-/$ - parietal cells), (6) mitochondria, (7) lamellar and dense bodies, (8) nucleoplasm, and (9) glycogen. Volume densities were calculated by dividing the number of points lying over a given structure by the total number of points counted over that parietal cell $[29,30]$.

2.4. Data Analysis. Data were analyzed using SAS V8.0, or 9.1 (SAS Institute, Cary NC), and Sigma Plot 2000. Means and standard errors of the means were determined by genotype, gender, treatment and age using the General Linear Model. For data shown in bar graphs, $n=$ an individual animal.
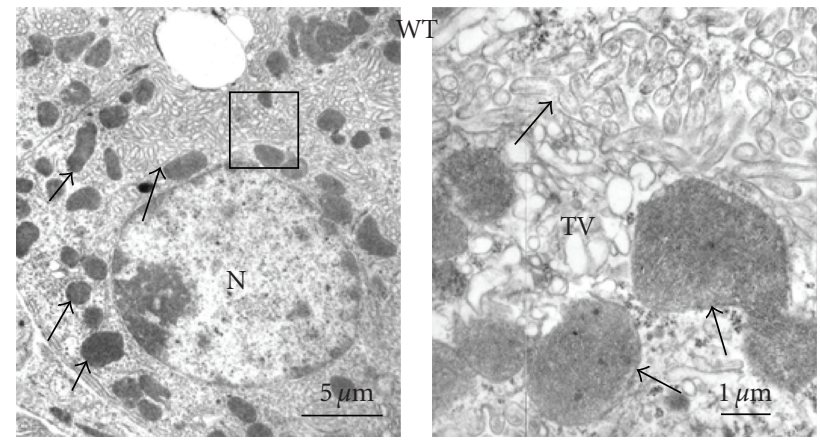

(a)
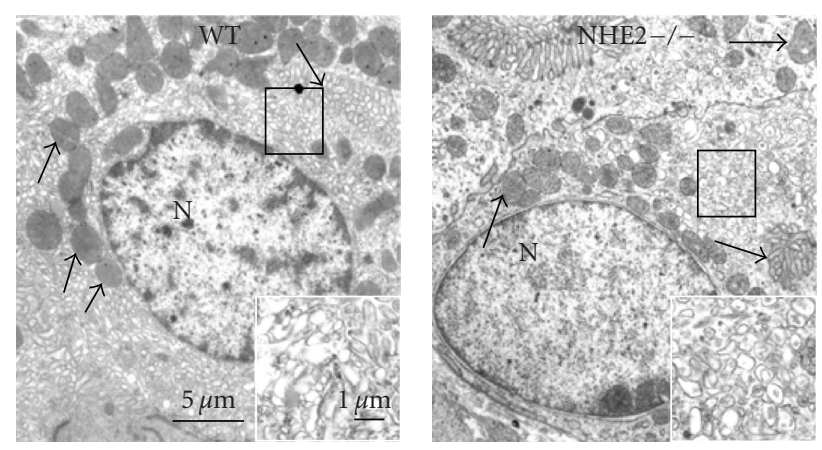

(b)

FIGURE 1: WT parietal cells (left and right). Right panel shows tubulovesicles similar to those boxed in (a). (b) Parietal cells from omeprazole treated mice: WT (left) and NHE2-/- (right). Insets show tubulovesicles from areas similar to those boxed in WT and NHE2-/- omeprazole-treated mice, respectively. Microvilli were significantly longer and the $\mathrm{Vd}$ of mitochondria was reduced in NHE2-/ - parietal cells compared to WT. Tubulovesicles in NHE2- / - parietal cells were mostly vesicular, and often contained electron-dense cores. N: nucleus; arrowheads: mitochondria; arrows: canaliculi, boxes surround TV.

Results were considered significant when $P \leq .05$. Images for final figures were scanned from prints, contrast enhanced, and occasionally dodged, burned, or the dust and scratches filter applied, when needed, with Photoshop 7 (Adobe.com). Figures were created with Corel Draw x3 (Kodak.com).

\section{Results}

3.1. Statistically Significant Markers of Acid Secretion. Parietal cells in the normochlorhydric KO mice (NHE1-/-, NHE3-/-, NKCC1-/- and PMCA4-/-) were not morphometrically different from WT mice, and these data were pooled (hereafter referred to collectively as WT). Generally, untreated WT parietal cell morphology and morphometry agreed very well with historical data (Figures 1 and 2). This was also true for those WT mice in which gastric acid secretion was inhibited by vagotomy or by omeprazole $[15,17,18]$ (Figure 1). Eighty-five to 90 percent of the cytoplasmic membranes, that is, $(\mathrm{TV}+\mathrm{CAM}) /$ total membranes were directly related to acid secretion in WT mice. 


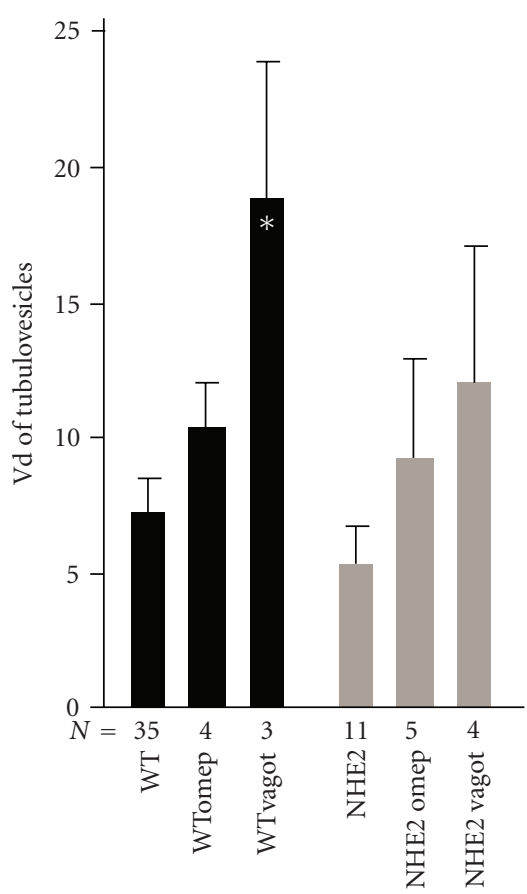

(a)

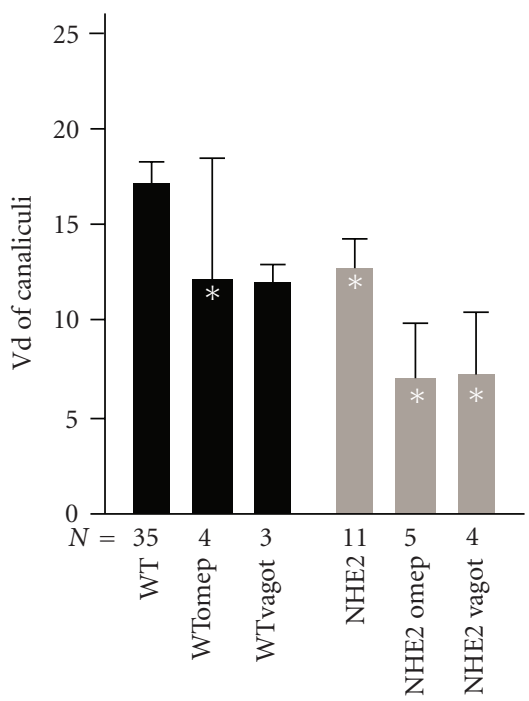

(c)

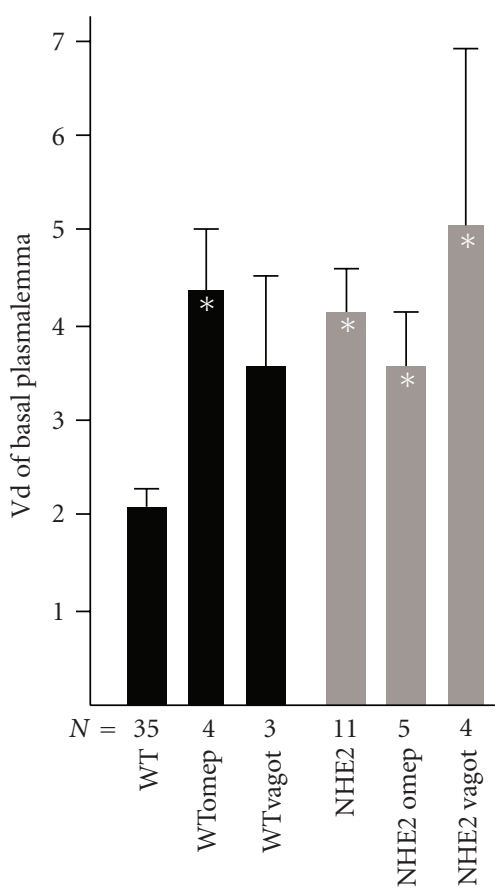

(b)

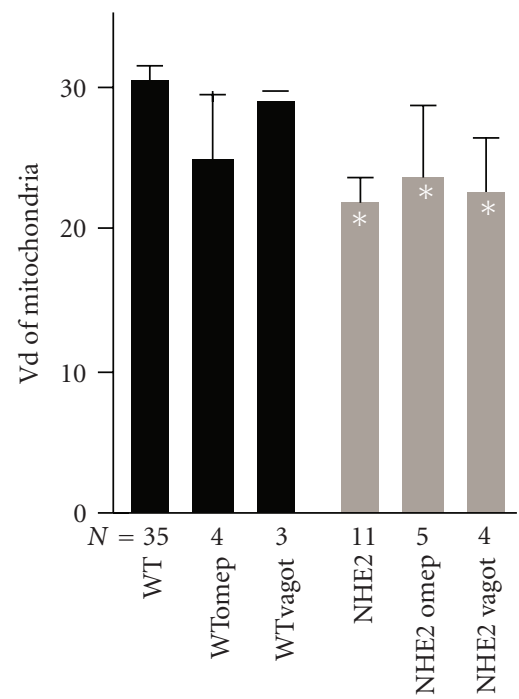

(d)

FIGURE 2: Vd of secretory membranes with and without inhibition of acid secretion with omeprazole (omep) or vagotomy (vagot) is shown for WT and NHE2-/- parietal cells. Black bars are WT, and grey bars are NHE2-/-. N: sample size. Asterisks denote significances of at least $P=.05$.

Data were ordered according to the number of $\mathrm{KO}$ genotypes which achieved a statistically significant difference from WT for each morphometric parameter (the number of achlorhydric genotypes significantly different from WT/the total number of achlorhydric genotypes tested): microvillar length and width (2/6), $\mathrm{Vd}$ of TV (3/6), Vd of basolateral membranes (4/6), Vd of lamellar and dense bodies (4/6), Vd of canaliculi (4/6), the Vd of all secretory membranes (5/6), and the VD of mitochondria (5/6) (Figure 2). The Vd of the nucleus showed no statistically significant changes among all groups (WT, normochlorhydric or achlorhydric) but data were put aside as incomplete because (1) the $\mathrm{Vd}$ of nuclear profiles appearing in micrographs was highly variable and (2) roles for cell volume regulation are predicted for AE2, NHE2, and NHE4.

The Vd of secretory membranes, grouped as TV plus CAM, was significantly reduced in four of the six achlorhydric KO groups only. In the GHKA $\alpha-/$ - genotype, canalicular nidi and vesicles were present but were round and contained within themselves smaller vesicles and thus 


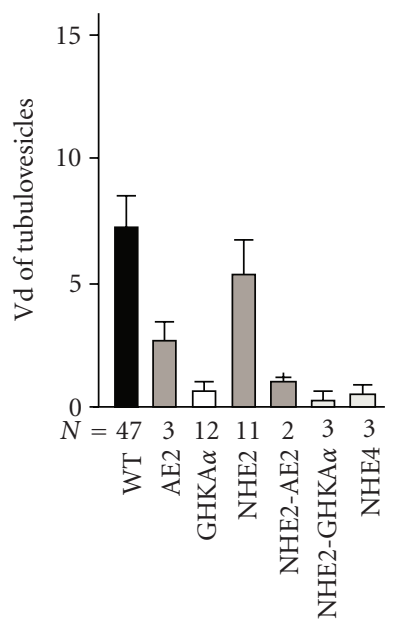

(a)

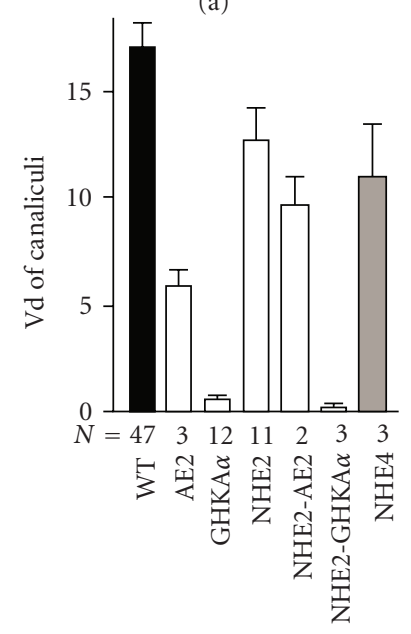

(c)

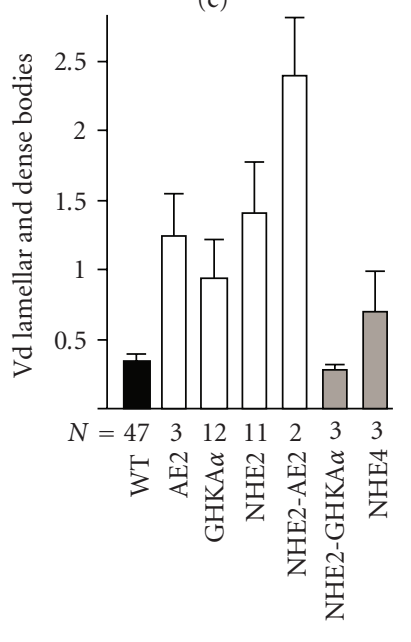

- WT

$\square P<0.05$ to WT pairs

$\square P=\mathrm{ns}$

$\square P<0.1$

(e)

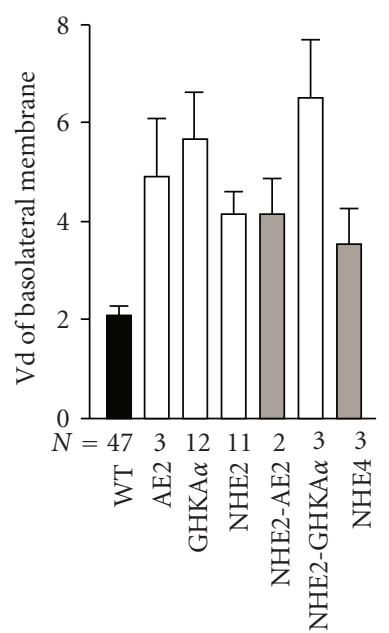

(b)

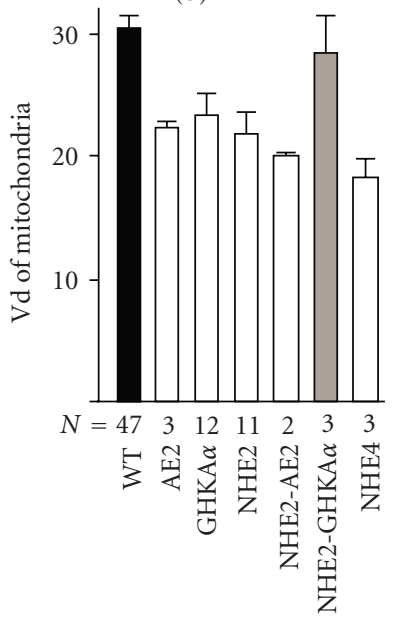

(d)

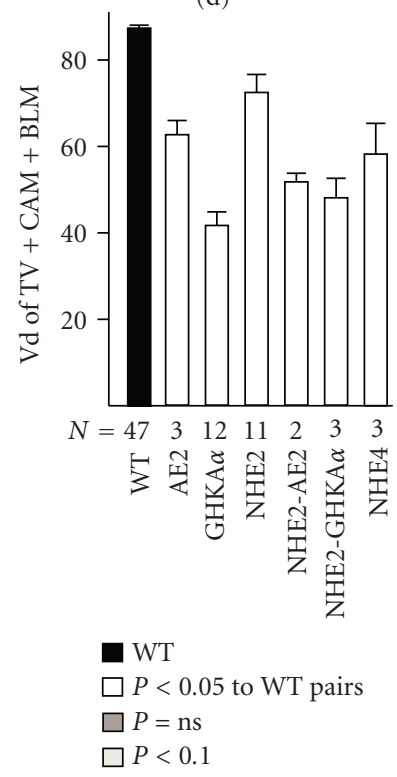

(f)

FIGURE 3: Volume density (Vd) of various membrane and organellar components of the parietal cells of WT and 6 achlorhydric genotypes are shown. Significant differences from WT $(P<.05)$ : white bars; marginal significances $(P<.1)$ : grey bars; and WT, to which all comparisons were made, black. The number of animals used in each comparison is given in the upper left graph, and names of the genotypes are below the bottom graphs in each column. Total secretory membranes = TV + CAM + BLM, being all membranes involved in balanced transport activities directly involved in acid secretion. 
were not typical of TV. This underscores the grey areas in interpretation as to what constituted CAM or TV. Several achlorhydric genotypes showed an absence of TVs or a decrease in TVs leading to a high ratio of CAM to TV, characteristics usually associated with stimulated acid secretion (Figures 2 and 3). We found that only the hypochlorhydric genotype, NHE2-/-, under both untreated and inhibited conditions, showed qualitatively similar responses in secretory membranes compared to WT, though quantitatively different (Figure 3).

Ratios of volume densities of various membranes and organelles were also used to see whether secretory membranes modulated reciprocally, since the latter has been suggested in several reports $[15,18]$, and to determine whether ratios would be of value for defining a stable histological phenotype of achlorhydria. Data were ranked again, according to how many achlorhydric genotypes showed significant differences in the ratios of volume densities, compared to untreated WT mice (Table 1).

The Vd of total secretory membrane/Vd of mitochondria was a fair predictor of gastric acid $\mathrm{pH}$, but not as good at predicting overall secretory activity in the knockout models as other parameters, because abnormal morphology (particularly in GHKA $\alpha-/-$ mice) produced misleading counts of CAM and TV. The following genotypes had very few vesicles (whether round or tubular) present in the cytoplasm: AE2-/-, NHE2-/- AE2-/-, and NHE4-/(Figure 3).

3.2. Modulation of TV, CAM, and BLM during Secretion and Quiescence. Our data also show that significant fluctuations (reductions or increases) in TV, CAM, and BLM occurred while the $\mathrm{Vd}$ of total secretory membranes remained nearly unchanged (Figure 2). Secretory membranes in WT mice were more or less equitably exchanged after vagotomy and omeprazole treatments. While some reports have demonstrated almost equal gains and losses within the whole secretory membrane compartment $[17,38-42]$, this was not the case with 5 of the 6 achlorhydric KOs. While equal gains and losses support the generally accepted hypothesis about modulation of membranes, it is implicit in this approach that all membranes be capable of modulating and those membranes to be included be named.

The sum of all secretory membranes (TV + CAM + BLM) showed a trend to increase in WT animals in which acid secretion was inhibited $(26.8 \pm 1.1$ versus $31.8 \pm 2.5$ $P=.07$ ), showing inequitable exchange, due in large part to a relatively greater increase in TV. In the NHE2-/- null mice where secretion was inhibited by vagotomy or omeprazole, no change in total Vd of secretory membranes occurred $(22.84 \pm 2.3$ versus $22.1 \pm 2.5 P=0.8)$, and changes were not significantly different than the paired untreated NHE2-/ - parietal cells. A decrease in the ratio of CAM to TV in both WT and NHE2-/- mice was significant during inhibition however, when each was compared to their respective untreated control (WT, $P=.0187$; NHE2-/-, $P=.023)$. Each was also accompanied by an increased $\mathrm{Vd}$ of basolateral membrane (significant only in WT, $P<.0001$ ). NHE2-/- mice were unique among the KO genotypes in this study because organelles changed in parallel (but not on a par) with WT mice.

The Vd of total secretory membranes was reduced, often severely, in the achlorhydric mice in this study, with $P$-values ranging between.058 and $<.0001$ for the 6 genotypes. In NHE2- - mice, where the reduction in secretory membranes was not as dramatic as the others KOs ( $P=.058)$, frequently the canalicular lumens were grossly dilated, accompanied by evidence of impending parietal cell death and debris (Figure 3 and [30]). The reduction in Vd of total secretory membranes, particularly in the NHE4-/-, NHE2-/-AE2-/-, and GHKA $\alpha-/-$ mice, resulted mostly from the loss of TV.

Inhibition of acid secretion, in our hands, produced an unbalanced membrane exchange in WT and NHE2-/parietal cells (Figure 2). Apical membranes with microvilli of an appropriate length and width, however, were clearly present in all $\mathrm{KO}$ genotypes except for the GHKA $\alpha-/-$ mice, where they were significantly shorter than in WT. Basolateral membranes were increased in all of the KOs but did not increase sufficiently to compensate for the loss of other secretory membranes, resulting in unbalanced modulation.

3.3. Tubulovesicles. TV were almost always visible in WT parietal cells, representing around $8 \%$ of the cell cytoplasm $(\mathrm{Vd}=7.68 \pm 0.96, n=47)$ (Figure 1) under normal conditions and were greatly increased when acid secretion was inhibited by vagotomy or omeprazole (13.99 \pm 2.73 $n=7, P=.010$ to untreated WT). Fasting and stimulation produced variable morphometric outcomes, especially in the $\mathrm{Vd}$ of $\mathrm{TV}$ in WT parietal cells, which varied from $0 \%$ to $100 \%$ of the secretory membranes in any given cell profile. This required the assessment of large numbers of micrographs of parietal cells, from many animals, to obtain representative data. When the morphology of TV was compromised, or when TVs were absent, gastric contents were less acidic. Unlike TVs, microvilli maintained a fairly constant morphology (GHKA $\alpha-/-$ parietal cells excepted). Thus, while the TV in some models did not reflect acid secretion, the morphology of TV gave important clues as to the causes of failed secretion, and highlighted the relatively unchanging appearance of CAM as well as mitochondria.

In NHE4-/- mice, TVs were dramatically reduced. Canalicular nidi were still present in the cytoplasm, and seemingly normal microvilli were seen on the apical membrane, but the cytoplasm just adjacent to the canaliculi was most often devoid of organelles and vesicles (whether round or tubular). Similarly, in AE2-/- mice, TVs were reduced (Vd $2.67 \pm 0.79 n=3, P=.033$ to WT)(Figure 3) but some round vesicles were observed. Even more dramatically, the NHE2-/-AE2-/- and NHE2-/-GHKA $\alpha-/-$ parietal cells had almost no vesicles at all (Figure 3 ).

3.4. Canaliculi. WT and NHE2-/- mice had no paucity of canaliculi and incipient canalicular nidi were frequently close to the basal portion of the parietal cells. No comment can be made in this study as to whether those nidi were separate from, or connected to, the infoldings of the apical 
TABLE 1: Number of achlorhydric mouse genotypes showing membrane Vd ratios significantly different than WT.

\begin{tabular}{lcl}
\hline Vd ratio & Number significant & Mouse Model \\
\hline TV+CAM+BLM/mitochondria & $2 / 6$ & GHKA $\alpha$, NHE2GHKA $\alpha$ \\
CAM /TV & $3 / 6$ & AE2, GHKA $\alpha$, NHE2, NHE2AE2 \\
Round vesicles/TV & $2 / 6$ & GHKA $\alpha$, NHE2GHKA $\alpha$ \\
All membranes/mitochondria & $5 / 6$ & AE2, GHKA $\alpha$, NHE2, NHE4 NHE2AE2 \\
BLM /mitochondria & $6 / 6$ & AE2, GHKA $\alpha$, NHE2, NHE4 NHE2AE2. NHE2GHKA $\alpha$ \\
\hline
\end{tabular}

Acid secretion was inhibited either by omeprazole treatment or vagotomy. Values for WT parietal cells with acid secretion inhibited were significantly different than untreated WT for Vd of CAM/TV, round vesicles/TV, and basolateral membrane/mitochondria. NHE2-/- inhibited parietal cells were not significantly different than NHE2-/- untreated.

membrane since 3D reconstruction from serial sections was not performed. Strikingly however, canaliculi in the cytoplasm of AE2-/-, NHE4-I-, and the NHE2-I- AE2-Imice were infrequent compared to WT (Figure 3), and invaginations were nearly always seen in close proximity to the apical membrane. Especially in the NHE2-/- AE2-Idouble KO parietal cells, there were no dilated canaliculi. In addition, glandular lumens were often filled with electron dense debris that was ultrastructurally similar to secretory granules from nearby zymogen cells (Figure 4(d)), which mimicked the single KO of AE2 [11]. Failure to generate deep cytoplasmic canalicular nidi, which become, or are already, part of the branched secretory CAM, was apparent in 3 of the $6 \mathrm{KO}$ genotypes. In contrast, the other three genotypes (GHKA $\alpha-/-$, NHE2-I-, and the NHE2-lGHKA $\alpha-/$ - double KO) showed sporadic, but often massive dilation of their canaliculi, with canalicular nidi seemingly deep in the cytoplasm and separate from the apical membrane.

3.5. Microvilli. Microvilli in WT mice were approximately $1 \mu \mathrm{m}$ long $\times 0.2 \mu \mathrm{m}$ wide, undulated modestly in thickness along their lengths, and were slightly bulbous at the ends. NHE2-/- parietal cells had normal microvillar morphology but they were significantly longer than in WT parietal cells (WT, $1.17 \pm 0.037$ by $0.26 \pm 0.012$ microns, $n=40$; NHE2-/,$- 2.04 \pm 0.65$ by $0.35 \pm 0.1$ microns, $n=13$, $P=.012$ ). Both microvillar length and width tended to decrease during inhibition of acid secretion (vagotomy and omeprazole, combined data) in WT and NHE2-/ - mice, but this did not reach statistical significance.

In opportune cross sections actin filaments within CAM were apparent, and most often arranged in a circle, close to the plasmalemma, but occasionally were found clustered centrally as a core bundle [28]. No quantification of the ratio of centrally to peripherally located actin was performed in the current study, but it was obvious, subjectively, that WT parietal cells had considerably more microvilli with peripherally located actin than with centrally bundled actin, while in the achlorhydric KOs the latter arrangement was much more frequent. Two genotypes were exceptions: (1) the hypochlorhydric NHE2-/- mice had actin located peripherally in the microvilli, again underscoring that the parietal cells in this $\mathrm{KO}$ must have some functional acid secretion, and (2) in the GHKA $\alpha-/-$ mice, where parietal cells always showed centrally bundled actin, microvilli were significantly shorter than in WT mice [29].

3.6. Basolateral Membranes. The increase in Vd of the basolateral membrane was significant in 4 of the 6 achlorhydric genotypes, and elevated in the other two (Figures 3 and 4). In addition to the $\mathrm{Vd}$ of the BLM being increased with achlorhydria, the normally closely aligned intercellular interdigitations give way to broader infoldings, that extended further into the cytoplasm than in WT cells (Figure 5). On occasion, basolateral infoldings showed a morphology very close to that of microvilli. (This is a rarely reported observation [15].) In NHE4-/- and AE2-/- mice, and in the NHE2-/- AE2-/- double KO especially, interdigitations were broader (Figure 5). The Vd of basolateral membranes alone was about equivalent to the $\mathrm{Vd}$ of canaliculi in predicting the level of acid secretion. However, when the $\mathrm{Vd}$ of BLM was expressed as a ratio with the $\mathrm{Vd}$ of mitochondria, the $\mathrm{p}$ values were significant for $6 / 6$ of the achlorhydric genotypes, thus making this ratio one of the better markers derived from morphometry.

3.7. Mitochondria. The Vd of mitochondria provided a reasonably good measure of acid secretory competence, being significantly reduced in 5 of 6 achlorhydric models compared to WT, reflecting decreased secretory activity. Mitochondria were also of quite stable morphology (Figure 3). Vd of mitochondria was about 30\% in WT parietal cells and was significantly reduced in parietal cells of NHE2-/mice (untreated), compared to WT. Inhibition of acid secretion with omeprazole or vagotomy did not decrease mitochondrial Vd further (Figure 2). Though mitochondrial Vd was reduced in the hypo- and achlorhydria phenotypes, mitochondria still appeared to be of normal size and shape, and cristi were unremarkable, and were overall quite similar to WT, except for the GHKA $\alpha$ KO. GHKA $\alpha-/-$ [29] and NHE2-/- GHKA $\alpha \alpha-/-$ double KO mice showed some very large mitochondria with whorled cristi in young animals (Figure 4), a phenotype which disappeared as the animals aged.

The position of mitochondria within WT parietal cells is characteristically closely juxtaposed to TV and CAM, and indeed, areas of TV and CAM are intimately surrounded by mitochondria. Several KO genotypes 

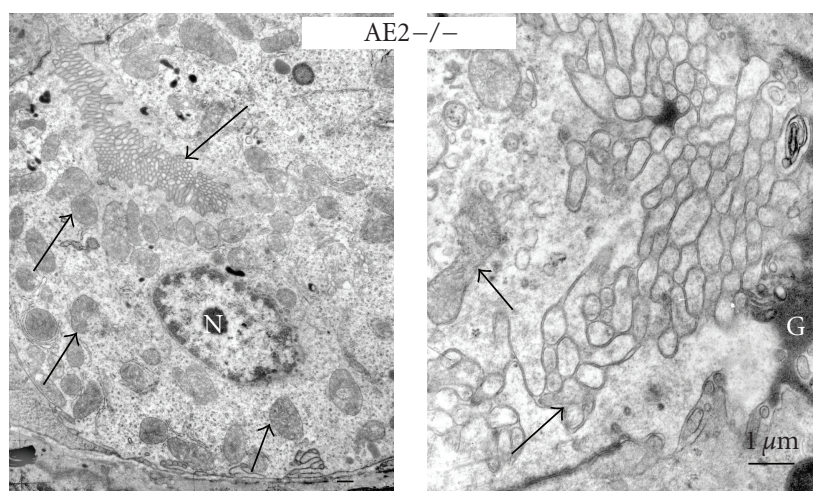

(a)

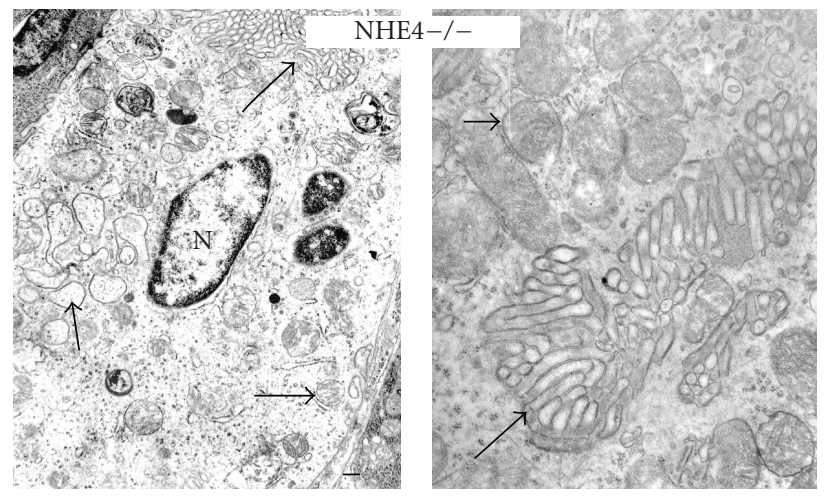

(c)

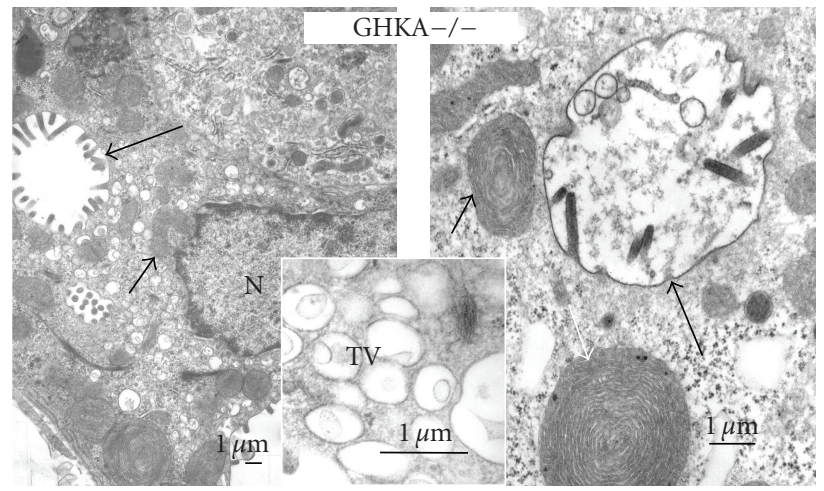

(b)

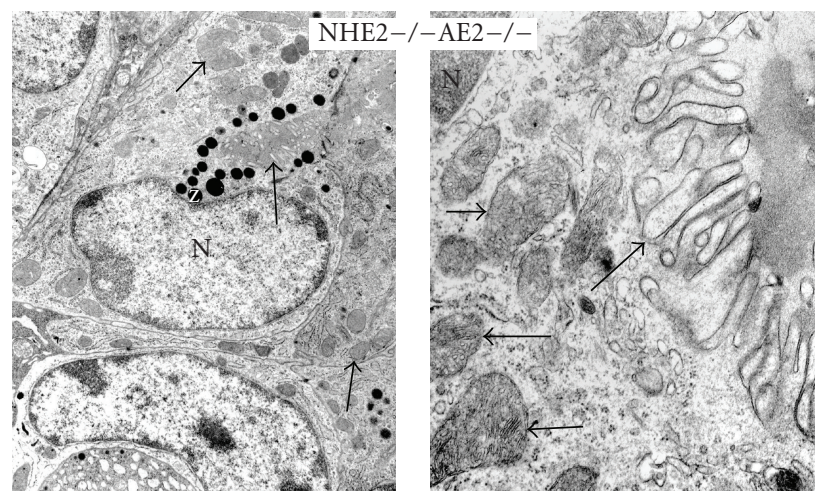

(d)

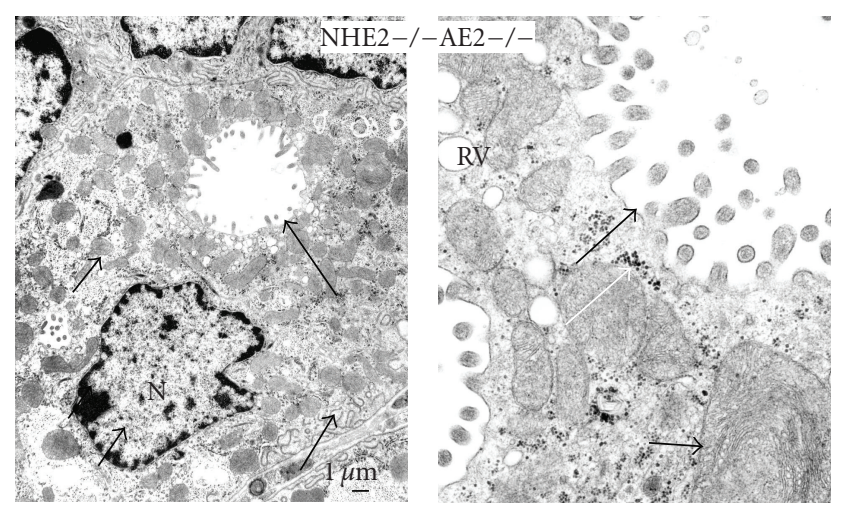

(e)

FIGURE 4: (a) AE2-/- parietal cells showed a reduction in TV, canalicular and mitochondrial Vd, and, seen at higher magnification, cytoplasm contained occasional polysomes but generally reduced numbers of organelles (compared to WT and NHE2-/- (see Figure 1)). Microvilli were mostly confined to the apical membrane, incipient canaliculi were equivocally identified, and electron-dense material often filled the gastric gland lumen (G). (b) The GHKA $\alpha-/$ - parietal cells showed short microvilli, round vesicles instead of TV, cytoplasmic glycogen, frequent canalicular dilatation, and occasionally, large mitochondria with whorled cristi. (c) and (d). The two genotypes that seemed to have the most organelle-depleted cytoplasm were the NHE4-/- (c) and the NHE2-/- AE2-/- double KO (d). Parietal cells in both of these genotypes were very sparsely inter-populated with organelles, having significant reductions in Vd of both membranes and mitochondria. (e) NHE2-/- GHKA $\alpha-/-$ parietal cells were quite similar to the GHKA $\alpha-/-$ single knockout. The latter two were the only genotypes which showed cytoplasmic glycogen or whorled cristi in mitochondria, and short stubby microvilli. For all panels: arrow heads: mitochondria; white arrowheads: mitochondria with whorled cristi; arrows: canaliculi, N: nucleus; Z (white) zymogen granule.

(NHE2-/-, GHKA $\alpha-/-$ and NHE2-/- GHKA $\alpha-/-)$ were similar in this regard. However, in NHE4-/- [12], AE2-/and NHE2-/- AE2-/ - parietal cells, mitochondria were positioned at a distance from CAM, rarely coming in close proximity to those membranes. Subjectively, the void zone was inversely related to the amount of TV and vesicular membranes present in the cytoplasm, and thus inversely related to the acid secretion. 
3.8. Dense and Lamellar Inclusions. Inclusion bodies, or phagolysosomes, the morphology of which was divided into two phenotypes in this study (dense granular and lamellar), were significantly increased in $4 / 6$ achlorhydric genotypes. Dense granular inclusions were almost exclusively found in the GHKA $\alpha-/$ - mice (GHKA $\alpha-/$ - and NHE2-IGHKA $\alpha-/-)$, appeared to be large, and composed of both dark and lucent rounded granules, lacking much in the way of myelin-like components. The remaining achlorhydric genotypes displayed myelin or lamellar-type inclusions with some granular components also. The highest $\mathrm{Vd}$ of lamellar inclusions was found in the NHE2-/- AE2-/- double KO mice $(P<.0001$ to WT) (Figure 3$)$. AE2 $-/-$ and NHE4- mice also showed a preponderance of lamellar type bodies, rather than dense granular inclusions (Figure 4).

Although the two different types of cytoplasmic inclusions, dense granular and lamellar, were combined into a single category for statistical purposes, they were very different in structure, and likely resulted from quite different mechanisms.

In NHE2-/- single KO mice, parietal cell death was elevated and cell debris containing large lamellar inclusions was common in the gastric gland lumens. The Vd of lamellar inclusions in NHE2-/- mice decreased upon inhibition of acid secretion by vagotomy or omeprazole (NHE2-1untreated $1.31 \pm 0.31, n=13$, versus NHE2 $-/$ - inhibited $0.76 \pm 0.37, n=9, P=.073$ ), suggesting that they may result from faulty modulation of TV and CAM. Interestingly, where the TVs were decreased because of loss of GHKA $\alpha$ in the double null mice, the $\mathrm{Vd}$ of lamellar inclusions diminished, but in the NHE2-/-AE2-/- null mice, it increased above that of the NHE2-I- single KO (Figure 3 ).

\section{Discussion}

Gastric acidity in WT mice parallels the relative volume densities of canalicular and apical membranes (CAM) and tubulovesicular membranes (TV) in the parietal cell cytoplasm in a predictable manner. [1, 3, 8, 14-19]. Although the relationship between the level of acid secretion and the relative amounts of CAM and TV has been useful as a reference point for histology, it is not without inconsistencies [40]. In addition, methods of long-term inhibition (omeprazole and vagotomy) have many undesirable secondary effects, such as hypergastrinemia [23] and changes in morphology. Just as problematic is the fact that adjacent parietal cells can vary widely in the Vd of TVs.

Our data from our normal parietal cells supported the occurrence of diminished Vd of TV with stimulation and a cytoplasm containing mostly TVs and only a few CAM after inhibition of acid secretion. During examination of the various mouse models of hypochlorhydria and achlorhydria it became clear that using the ratio of CAM to TV was not an unambiguous indicator of activity. Our ultrastructural quantification of CAM and TV and other membranes and organelles in mice which were normochlorhydric, compared with 6 mouse models with defective acid secretion, demonstrated that the Vd of TV was more variable than other organelles when predicting secretory competence. In fact, the Vd of basolateral membranes, and mitochondria, and the ratio of these two parameters, paralleled the gastric $\mathrm{pH}$ data from published studies far better. The most critical event in disrupting the ratio of CAM to TV appeared to involve the interruption of vesicle trafficking between TV and CAM. This was alluded to in the AE2-/ - and NHE4-/single KOs $[11,12,30]$ and the NHE2-/- AE2-/- double $\mathrm{KO}$, but comparisons clearly suggest that with significant decreases in Vd of TV, there is little acid secretion. TV appeared to vary morphologically (and morphometrically) independently from CAM, since even in an almost total absence of both round vesicles and TV, the presence of an ultrastructurally "normal-looking" canalicular and apical membrane microvillar morphology can persist. This raises the question of whether minute amounts of acid are being secreted from these ostensibly normal looking microvilli.

Another complicating issue was the identification of TV. Shape (whether round or tubular) and location with respect to mitochondria and canaliculi were subject to viewer judgement [20], and physical factors such as buffering and fixation greatly influenced the appearance of TV $[15,38]$. Consistently applied criteria for "tubular and vesicular" shape were used in this study. If a vesicle appeared to be "round" rigid, infrequent, and not located in proximity to CAM, then it was not counted as TV. In one of the few papers which quantified parietal cells in achlorhydric mice (these lacked ezrin [20]) a significant increase in TV and apical membranes in parietal cells was shown, but in images from that study, apical membrane microvilli looked disorganized and were reduced in amount compared to their WT controls, and what was identified as a vesicular component resembled the rounded vesicles in GHKA $\alpha-/-$ parietal cells (Figure 4) in our study.

Our data suggest that a common hindrance to acid secretion is the loss of membrane modulation, vesicle fusion or fission events, or other factors, leading to a block in the formation of TV. The morphology of TV and other membranes is important clues as to the causes of failed secretion, but the relatively unchanging appearance of CAM and mitochondria may be better equated with overall parietal cell acid secretion. Emerging studies demonstrate the importance of proteins such as the F-actin- and clathrinbinding protein Huntingtin interacting protein 1 related (Hip1r) in vesicular trafficking for parietal cell acid secretion. In addition, the gastric morphogen Sonic Hedgehog (Shh) is also involved in activation of parietal cell function possibly via membrane modulation [43]. In contrast to the ezrin and GHKA $\alpha-/-$ mouse models $[22,28,29]$ both the Hip1r [44] and the parietal cell-specific Shh null animals [43] lack well-defined tubulovesicles and exhibit expanded canalicular membranes. Neither of the latter mouse models respond to histamine stimulation, perhaps with important implications for other models of secretion.

Failure to generate deep separate cytoplasmic canalicular nidi (which become, or are already, part of the branched secretory CAM) was apparent in 3 of the $6 \mathrm{KO}$ genotypes. In contrast, the other three genotypes (GHKA $\alpha-/-$, NHE2-/-, and the NHE2-/- GHKA $\alpha-/-$ double KOs) 


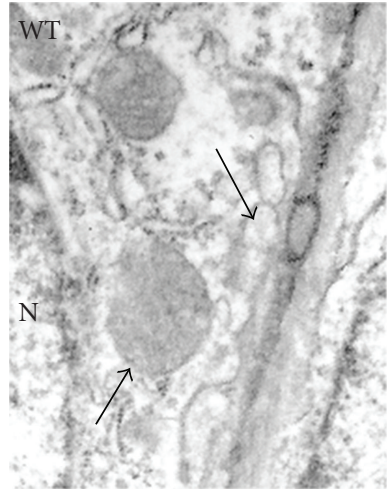

(a)

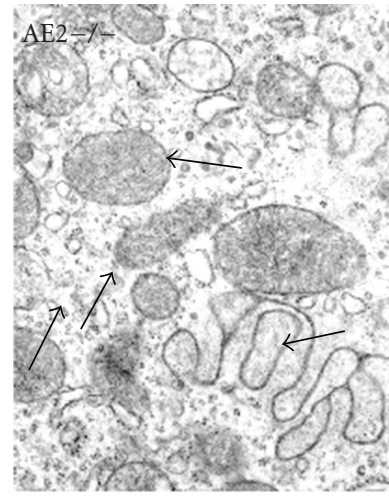

(b)

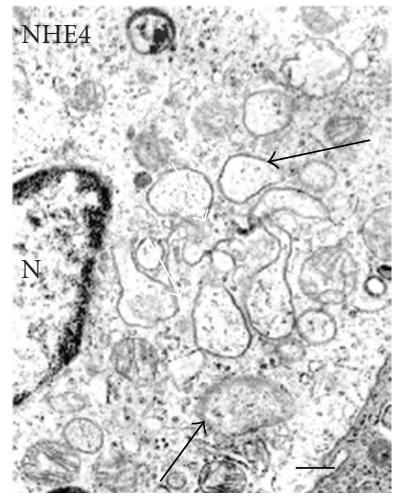

(c)

Figure 5: WT (a) basolateral membrane shows mostly parallel or slightly undulating infoldings. AE2-/- (b) and NHE4-/- (c) showed the significantly increased Vd of basolateral membranes infoldings typical of achlorhydric mice. In addition, loops and interdigitations were broadened in width. Arrowheads: mitochondria; N: nucleus, interdigitations: long arrows; bar: 1 micron for all images.

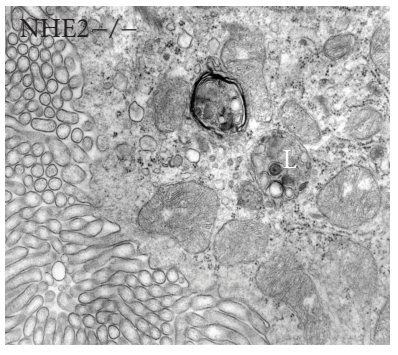

(a)

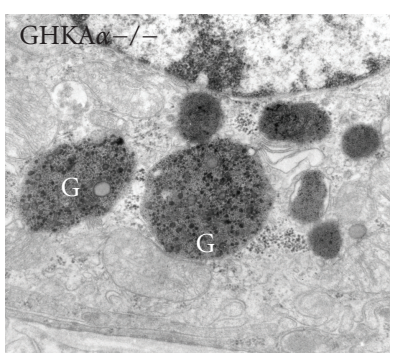

(c)

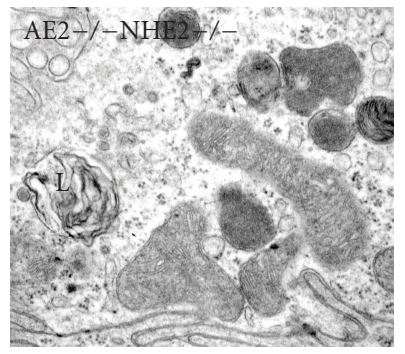

(b)

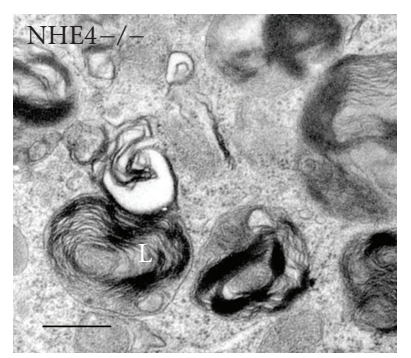

(d)
FIGURE 6: Lamellar and dense granular bodies were uncommon in WT parietal cell cytoplasm (see Figure 1). Lamellar inclusions were increased in NHE2-I-, AE2-I- and NHE2-I- AE2-Imice. Lamellar inclusions decreased in the NHE2-/- parietal cells when secretion was inhibited. In GHKA $\alpha-/-$ mice, inclusions were almost always dense and granular. L, lamellar inclusions, G dense granular inclusions; bar: 1 micron for all.

showed sporadic, but often massive dilation of their canaliculi, with canalicular nidi seemingly deep in the cytoplasm and separate from the apical membrane. The ezrin KO mouse [20] showed CAM which seemed to be derived from short invaginations from the apical membrane, but not from deeper nidi in the cytoplasm. Common between the ezrin $\mathrm{KO}$ and the GHKA $\alpha-/$ - was that both apparently failed to connect actin filaments to the secretory membranes $[20,28]$.
Reports reveal that the loss of proteins critical for acid secretion sometimes results in dramatic ultrastructural consequences, as was seen in parietal cells of mice lacking GHKA $\alpha[13,28,29]$. In other models, less dramatic ultrastructural changes were found, such as those reported for the NHE2-/- mouse [30], where we also observed that both CAM and TV appeared to modulate appropriately. It is important to point out that in the NHE2-/- mice the loss of acid secretion appeared to be due primarily to diminished parietal cell viability, reduced parietal cell numbers, and increased base secretion [30]. Parietal cells in young NHE2-/- mice can actually show highly developed CAM and numerous TV and overall, present with a fairly normal morphology.

F-actin and ezrin regulate movement of vesicles and organelles through the cytoplasm, are essential for modulation of parietal cell membranes in gastric acid secretion $[7,20,45]$, and also interact with some major transport proteins, including the gastric H,K-ATPase (GHKA) [28, 29]. As surmised from the GHKA $\alpha$ KO mouse, microvillar ultrastructure requires the presence of GHKA $\alpha$ and the linking of actin to the microvillar membrane, and is also necessary for the modulation of CAM to TV and vice versa. Similar reports emanated from the knockout of the GHKA $\beta \beta$ subunit [22]. It has been reported that the distribution of ezrin is at the interface of TV and CAM and that it participates in membrane-vesicle fusion and movement events [46,47], regardless of the controversy over whether TV and CAM are distinct, continuous, or both, and in what manner they are recycled and recruited $[8,42,48]$.

Whether secretory membranes in WT mice were equitably exchanged after vagotomy and omeprazole treatments has also been in question. Our data show that significant fluctuations (reductions or increases) in TV, CAM, and BLM occurred while the Vd of total secretory membranes remained nearly unchanged. According to Ito and Schofield [15], during stimulation of acid secretion with insulin, microvillar membranes increased from $12 \%$ to $20 \%$, lateral and basal cell membranes decreased from $6 \%$ to $5 \%$, and 
there was a simultaneous reduction in tubulovesicular membranes from a Vd of about $24 \%$ in untreated, to around $4 \%$ in stimulated cells. Helander [38] also implied an even exchange of membranes (in this case TV and CAM) during stimulation of acid secretion. Other studies have demonstrated almost equal gains and losses within the whole secretory membrane compartment $[17,38,39]$. The inhibition of acid secretion, in our experiments, produced an unbalanced membrane exchange in both WT and NHE2-/- parietal cells and also was of a lesser magnitude than what others reported [15]. While equal gains and losses support a generally accepted hypothesis, it is implicit in this approach that all membranes must first be able to modulate.

Vd of basolateral membranes was approximately doubled in achlorhydria and hypochlorhydria. Even then, it comprises only a few percent of the total membrane $\mathrm{Vd}$ in parietal cells and this increase would appear to be insufficient to compensate for the large fluctuations in the $\mathrm{Vd}$ of TV and CAM. It is clear, of course, that basal and lateral membranes form a separate compartment from that of secretory membranes (TV and CAM), and too that combining them into one category is an oversimplification. The microenvironment that basal portions of the plasmalemma abut has a completely different milieu than lateral membanes. Evidence in support of the involvement of basolateral membrane processes in acid secretion comes from the required activation of $\mathrm{Cl}^{-} / \mathrm{HCO}_{3}^{-}$and $\mathrm{Na}^{+} / \mathrm{H}^{+}$ exchangers on the basolateral membrane $[11,12,49]$. These ion exchangers are critical components of the overall system of basolateral transporters needed to support ongoing $\mathrm{HCl}$ and $\mathrm{KCl}$ secretion across canalicular membranes. Somewhat counterintuitively, however, in this study we found a significant increase in $\mathrm{Vd}$ of basolateral membranes when acid secretion was diminished. The increased basolateral infoldings observed in achlorhydric phenotypes may be due to a "physical" effect: a compensation for changes in cell shape accompanying the greatly reduced canalicular space, which normally extends deep into the parietal cell cytoplasm during stimulated secretion. The activation of secretion might result in fewer infoldings as the cell expands and the infoldings are drawn into the surface plasmalemma. However, when reduced acid secretion was accompanied by increased canalicular space, $\mathrm{Vd}$ of basal and lateral membranes was still increased (as was seen in the NHE2-/- and GHKA $\alpha$ parietal cells). NHE2-/- and GHKA $\alpha-/-$ mice, with their often greatly enlarged "intercellular" canalicular space, still had significantly increased Vd of basolateral membranes. Basolateral membranes are also critical sites of ligand binding (acetylcholine, gastrin, histamine) for regulation of acid secretion, and it is possible that the $\mathrm{Vd}$ of basolateral membranes is regulated separately from the Vd of TV and CAM.

The Vd of mitochondria was about $30 \%$ in the WT parietal cells in this study, which was very close to reports in the literature $[11,12,15,18,29,30,36,38,39,50,51]$. Duman et al. [8] obtained a mitochondrial Vd of $40 \%$, but this was after excluding nuclei and canalicular space from the analysis and was therefore higher than the values for our WT and achlorhydric mice. Mitochondrial Vd appeared not to fluctuate after stimulation or inhibition of secretion in the short term $[15,38]$ but it did decrease under conditions of chronic inhibition (WT, vagotomy, and omeprazole) as shown in the current study. Mitochondrial Vd was significantly reduced in untreated NHE2-/- mice, and inhibition with omeprazole and vagotomy did not decrease it further (Figure 2). Vd of mitochondria was an improved indicator of achlorhydria, perhaps posing better as an overall indicator of cell activity, reflecting principally, acid secretion. Mitochondria within WT parietal cells were typically closely juxtaposed to TV and CAM, and indeed, areas of TV and CAM and mitochondria were intimately associated in WT and in NHE2-/- parietal cells, and in GHKA $\alpha-/-$ parietal cells to some degree. Uncharacteristically however, and especially prominent in the NHE4-/- KO [12], but also in AE2-/ - and NHE2-/- AE2-/ - double KO parietal cells, mitochondria were positioned quite a distance from CAM, rarely coming in close proximity to those membranes. Images from Recalde et al. [21] showed AE2-/- parietal cells which clearly pointed to a decreased Vd of mitochondria and a greater separation between mitochondria, TV, and CAM. Subjectively, the void zone is inversely related to the amount of TV and vesicular membranes present in the cytoplasm and inversely related to measured acid secretion.

Inclusion bodies were consistently increased with achlorhydria. It is possible, perhaps, that pentalamellar bodies [14] were coincident in a few instances with lamellar bodies, or that they may fall into the same membrane recycling cascade as lamellar bodies. Sawaguchi [14] mentioned that dense autophagolysosomes were heavily invested with the gastric $\mathrm{H}^{+}, \mathrm{K}^{+}$ATPase. What is interesting is that lamellar inclusions were common in all genotypes except those where GHKA $\alpha$ was lacking.

In summary, using various knockout mouse models in which acid secretion was impaired and experimentally induced inhibition of acid secretion it was determined that the ratio of CAM to TV was a good indicator of acid secretion in parietal cells which have functional membrane trafficking potential. NHE2-/- mice had the capacity to modulate secretory membranes and showed a parallel response to WT parietal cells in morphometry and morphology, though attenuated. However, it was more common for defects in membrane trafficking to produce atypical ratios of TV to CAM. It appears that the $\mathrm{Vd}$ of mitochondria and $\mathrm{Vd}$ of basolateral membranes and the ratio of the two, are measures which can be applied both to WT and achlorhydric models that reflect the level of gastric acid secretion.

\section{Acknowledgments}

This research was funded in part by ES 06096 and DK 50594. The authors thank Angel Whittaker and Maureen Bender for expert animal husbandry.

\section{References}

[1] T. Urushidani and J. G. Forte, "Signal transduction and activation of acid secretion in the parietal cell," Journal of Membrane Biology, vol. 159, no. 2, pp. 99-111, 1997. 
[2] E. Lindström, L. Eliasson, M. Björkqvist, and R. Håkanson, "Gastrin and the neuropeptide PACAP evoke secretion from rat stomach histamine-containing (ECL) cells by stimulating influx of $\mathrm{Ca}^{2+}$ through different $\mathrm{Ca}^{2+}$ channels," Journal of Physiology, vol. 535, no. 3, pp. 663-677, 2001.

[3] X. Yao, S. M. Karam, M. Ramilo, et al., "Stimulation of gastric acid secretion by cAMP in a novel alpha-toxin-permeabilized gland model," American Journal of Physiology, vol. 271, no. 1, part 1, pp. C61-C73, 1996.

[4] Y. Kato, H. Fukamachi, M. Takano-Maruyama, et al., "Reduction of SNAP25 in acid secretion defect of Foxl1-/- gastric parietal cells," Biochemical and Biophysical Research Communications, vol. 320, no. 3, pp. 766-772, 2004.

[5] B. C. Calhoun and J. R. Goldenring, "Rab proteins in gastric parietal cells: evidence for the membrane recycling hypothesis," Yale Journal of Biology and Medicine, vol. 69, no. 1, pp. 1-8, 1996.

[6] G. J. Dockray, "Gastrin and gastric epithelial physiology," Journal of Physiology, vol. 518, no. 2, pp. 315-324, 1999.

[7] A. Pagliocca, P. Hegyi, V. Venglovecz, et al., "Identification of ezrin as a target of gastrin in immature mouse gastric parietal cells," Experimental Physiology, vol. 93, no. 11, pp. 1174-1189, 2008.

[8] J. G. Duman, G. Singh, G. Y. Lee, T. E. Machen, and J. G. Forte, " $\mathrm{Ca}^{2+}$ and $\mathrm{Mg}^{2+} / \mathrm{ATP}$ independently trigger homotypic membrane fusion in gastric secretory membranes," Traffic, vol. 3, no. 3, pp. 203-217, 2002.

[9] S. Karvar, X. Yao, J. G. Duman, K. Hybiske, Y. Liu, and J. G. Forte, "Intracellular distribution and functional importance of vesicle-associated membrane protein 2 in gastric parietal cells," Gastroenterology, vol. 123, no. 1, pp. 281-290, 2002.

[10] J.-S. Yang, H. Gad, S. Y. Lee, et al., "A role for phosphatidic acid in COPI vesicle fission yields insights into Golgi maintenance," Nature Cell Biology, vol. 10, no. 10, pp. 1146-1153, 2008.

[11] L. R. Gawenis, C. Ledoussal, L. M. Judd, et al., "Mice with a targeted disruption of the $\mathrm{AE} 2 \mathrm{Cl}^{-} / \mathrm{HCO}_{3}^{-}$exchanger are achlorhydric," Journal of Biological Chemistry, vol. 279, no. 29, pp. 30531-30539, 2004.

[12] L. R. Gawenis, J. M. Greeb, V. Prasad, et al., "Impaired gastric acid secretion in mice with a targeted disruption of the NHE4 $\mathrm{Na}^{+} / \mathrm{H}^{+}$exchanger," Journal of Biological Chemistry, vol. 280, no. 13, pp. 12781-12789, 2005.

[13] L. M. Judd, A. Andringa, C. A. Rubio, Z. Spicer, G. E. Shull, and M. L. Miller, "Gastric achlorhydria in H/KATPase-deficient (Atp4a(-/-)) mice causes severe hyperplasia, mucocystic metaplasia and upregulation of growth factors," Journal of Gastroenterology and Hepatology, vol. 20, no. 8, pp. 1266-1278, 2005.

[14] A. Sawaguchi, F. Aoyama, M. Ohashi, S. Ide, and T. Suganuma, "Ultrastructural transformation of gastric parietal cells reverting from the active to the resting state of acid secretion revealed in isolated rat gastric mucosa model processed by high-pressure freezing," Journal of Electron Microscopy, vol. 55, no. 2, pp. 97-105, 2006.

[15] S. Ito and G. C. Schofield, "Studies on the depletion and accumulation of microvilli and changes in the tubulovesicular compartment of mouse parietal cells in relation to gastric acid secretion," Journal of Cell Biology, vol. 63, no. 2, part 1, pp. 364-382, 1974.

[16] J. G. Forte and X. Yao, "The membrane-recruitment-andrecycling hypothesis of gastric $\mathrm{HCl}$ secretion," Trends in Cell Biology, vol. 6, no. 2, pp. 45-48, 1996.

[17] H. F. Helander and B. I. Hirschowitz, "Quantitative ultrastructural studies on inhibited and on partly stimulated gastric parietal cells," Gastroenterology, vol. 67, no. 3, pp. 447-452, 1974.

[18] G. C. Schofield, S. Ito, and R. P. Bolender, "Changes in membrane surface areas in mouse parietal cells in relation to high levels of acid secretion," Journal of Anatomy, vol. 128, part 4, pp. 669-692, 1979.

[19] T. Ogata and Y. Yamasaki, "Morphological studies on the translocation of tubulovesicular system toward the intracellular canaliculus during stimulation of the gastric parietal cell," Microscopy Research and Technique, vol. 48, no. 5, pp. 282-292, 2000.

[20] A. Tamura, S. Kikuchi, M. Hata, et al., "Achlorhydria by ezrin knockdown: defects in the formation/expansion of apical canaliculi in gastric parietal cells," Journal of Cell Biology, vol. 169, no. 1, pp. 21-28, 2005.

[21] S. Recalde, F. Muruzabal, N. Looije, et al., "Inefficient chronic activation of parietal cells in Ae2a,b-/- mice," American Journal of Pathology, vol. 169, no. 1, pp. 165-176, 2006.

[22] K. L. Scarff, L. M. Judd, B. H. Toh, et al., "Gastric $\mathrm{H}\left({ }^{+}\right), \mathrm{K}\left({ }^{+}\right)$adenosine triphosphatase beta subunit is required for normal function, development, and membrane structure of mouse parietal cells," Gastroenterology, vol. 117, no. 3, pp. 605-618, 1999.

[23] D. Chen, C.-M. Zhao, R. Håkanson, L. C. Samuelson, J. F. Rehfeld, and L. Friis-Hansen, "Altered control of gastric acid secretion in gastrin-cholecystokinin double mutant mice," Gastroenterology, vol. 126, no. 2, pp. 476-487, 2004.

[24] T. Jons, B. Warrings, A. Jons, and D. Drenckhahn, "Basolateral localization of anion exchanger 2 (AE2) and actin in acidsecreting (parietal) cells of the human stomach," Histochemistry, vol. 102, no. 4, pp. 255-263, 1994.

[25] H. Rossmann, T. Sonnentag, A. Heinzmann, et al., "Differential expression and regulation of $\mathrm{Na}^{+} / \mathrm{H}^{+}$exchanger isoforms in rabbit parietal and mucous cells," American Journal of Physiology, vol. 281, no. 2, pp. G447-G458, 2001.

[26] S. L. Alper, A. Stuart-Tilley, C. F. Simmons, D. Brown, and D. Drenckhahn, "The fodrin-ankyrin cytoskeleton of choroid plexus preferentially colocalizes with apical $\mathrm{Na}^{+} \mathrm{K}^{+}$-ATPase rather than with basolateral anion exchanger AE2," Journal of Clinical Investigation, vol. 93, no. 4, pp. 1430-1438, 1994.

[27] R. R. Kopito, "Molecular biology of the anion exchanger gene family," International Review of Cytology, vol. 123, pp. 177199, 1990.

[28] M. L. Miller, L. M. Judd, I. R. Van Driel, et al., "The unique ultrastructure of secretory membranes in gastric parietal cells depends upon the presence of $\mathrm{H}^{+}, \mathrm{K}^{+}$-ATPase," Cell and Tissue Research, vol. 309, no. 3, pp. 369-380, 2002.

[29] Z. Spicer, M. L. Miller, A. Andringa, et al., "Stomachs of mice lacking the gastric $\mathrm{H}, \mathrm{K}$-ATPase $\alpha$-subunit have achlorhydria, abnormal parietal cells, and ciliated metaplasia," Journal of Biological Chemistry, vol. 275, no. 28, pp. 21555-21565, 2000.

[30] P. J. Schultheis, L. L. Clarke, P. Meneton, et al., "Targeted disruption of the murine $\mathrm{Na}^{+} / \mathrm{H}^{+}$exchanger isoform 2 gene causes reduced viability of gastric parietal cells and loss of net acid secretion," Journal of Clinical Investigation, vol. 101, no. 6, pp. 1243-1253, 1998.

[31] K. Park, R. L. Evans, G. E. Watson, et al., "Defective fluid secretion and $\mathrm{NaCl}$ absorption in the parotid glands of $\mathrm{Na}^{+} / \mathrm{H}^{+}$exchanger-deficient mice," Journal of Biological Chemistry, vol. 276, no. 29, pp. 27042-27050, 2001.

[32] Y. Guan, J. Dong, L. Tackett, J. W. Meyer, G. E. Shull, and M. H. Montrose, "NHE2 is the main apical NHE in mouse colonic crypts but an alternative $\mathrm{Na}^{+}$-dependent acid extrusion mechanism is upregulated in NHE2-null mice," 
American Journal of Physiology, vol. 291, no. 4, pp. G689G699, 2006.

[33] J. H. Pizzonia, D. Biemesderfer, A. K. Abu-Alfa, et al., "Immunochemical characterization of $\mathrm{Na}^{+} / \mathrm{H}^{+}$exchanger isoform NHE4," American Journal of Physiology, vol. 275, no. 4, part 2, pp. F510-F517, 1998.

[34] P. J. Schultheis, L. L. Clarke, P. Meneton, et al., "Renal and intestinal absorptive defects in mice lacking the NHE3 $\mathrm{Na}^{+} / \mathrm{H}^{+}$ exchanger," Nature Genetics, vol. 19, no. 3, pp. 282-285, 1998.

[35] S. M. Bell, C. M. Schreiner, P. J. Schultheis, et al., "Targeted disruption of the murine Nhel locus induces ataxia, growth retardation, and seizures," American Journal of Physiology, vol. 276, no. 4, part 1, pp. C788-C795, 1999.

[36] M. Flagella, L. L. Clarke, M. L. Miller, et al., "Mice lacking the basolateral $\mathrm{Na}-\mathrm{K}-2 \mathrm{Cl}$ cotransporter have impaired epithelial chloride secretion and are profoundly deaf," Journal of Biological Chemistry, vol. 274, no. 38, pp. 26946-26955, 1999.

[37] G. W. Okunade, M. L. Miller, G. J. Pyne, et al., "Targeted ablation of plasma membrane $\mathrm{Ca}^{2+}$-ATPase (PMCA) 1 and 4 indicates a major housekeeping function for PMCA1 and a critical role in hyperactivated sperm motility and male fertility for PMCA4," Journal of Biological Chemistry, vol. 279, no. 32, pp. 33742-33750, 2004.

[38] H. F. Helander, “The cells of the gastric mucosa," International Review of Cytology, vol. 70, pp. 217-289, 1981.

[39] C. A. Zalewsky and F. G. Moody, "Stereological analysis of the parietal cell during acid secretion and inhibition," Gastroenterology, vol. 73, no. 1, pp. 66-74, 1977.

[40] J. M. Pettit, I. R. van Driel, B.-H. Toh, and P. A. Gleeson, "From coiled tubules to a secretory canaliculus: a new model for membrane transformation and acid secretion by gastric parietal cells," Trends in Cell Biology, vol. 6, no. 2, pp. 49-53, 1996.

[41] X. Yao and J. G. Forte, "Cell biology of acid secretion by the parietal cell," Annual Review of Physiology, vol. 65, pp. 103131, 2003.

[42] T. Ogata and Y. Yamasaki, "The tubulovesicular system of gastric parietal cells is connected to the intracellular canaliculus, rough endoplasmic reticulum and Golgi complex. A study by high resolution scanning electron microscopy," Italian Journal of Anatomy and Embryology, vol. 106, no. 2, supplement 1, pp. 323-328, 2001.

[43] C. Xiao, S. Ogle, M. A. Orr-Asman, et al., "Parietal cellexpressed sonic hedgehog is required for maintenance of a functional and differentiated gastric epithelium," Gastroenterology. In press.

[44] R. N. Jain, A. A. Al-Menhali, T. M. Keeley, et al., "Hip $1 \mathrm{r}$ is expressed in gastric parietal cells and is required for tubulovesicle formation and cell survival in mice," Journal of Clinical Investigation, vol. 118, no. 7, pp. 2459-2470, 2008.

[45] A. S. DePina and G. M. Langford, "Vesicle transport: the role of actin filaments and myosin motors," Microscopy Research and Technique, vol. 47, no. 2, pp. 93-106, 1999.

[46] A. Sawaguchi, F. Aoyama, S. Ide, and T. Suganuma, "The cryofixation of isolated rat gastric mucosa provides new insights into the functional transformation of gastric parietal cells: an in vitro experimental model study," Archives of Histology and Cytology, vol. 68, no. 3, pp. 151-160, 2005.

[47] A. Luini, A. A. Mironov, M. A. De Matteis, and G. Griffiths, "The morpho-functional organization of secretory traffic. Here today, where tomorrow?” Medicina Nei Secoli, vol. 19, no. 1, pp. 29-54, 2007.

[48] B. J. Agnew, J. G. Duman, C. L. Watson, D. E. Coling, and J. G. Forte, "Cytological transformations associated with parietal cell stimulation: critical steps in the activation cascade," Journal of Cell Science, vol. 112, no. 16, pp. 2639-2646, 1999.

[49] S. Muallem, D. Blissard, E. J. Cragoe Jr., and G. Sachs, "Activation of the $\mathrm{Na}^{+} / \mathrm{H}^{+}$and $\mathrm{Cl}^{-} / \mathrm{HCO}_{3}^{-}$exchange by stimulation of acid secretion in the parietal cell," Journal of Biological Chemistry, vol. 263, no. 29, pp. 14703-14711, 1988.

[50] E. V. Kiseleva, A. G. Shilov, and N. B. Khristoliubova, "An electron microscopic and morphometric study of the gastric parietal cells of rats following administration of gastrin, histamine and cyclic 3',5' -adenosine monophosphate," Arkhiv Anatomii Gistologii Embriologii, vol. 69, no. 12, pp. 29-32, 1975.

[51] I. A. Morozov, "Topographic features of the ultrastructure of parietal cells of the gastric mucosa (morphometric study)," Biulleten' Eksperimental'noй Biologii i Meditsiny, vol. 82, no. 11, pp. 1390-1394, 1976. 

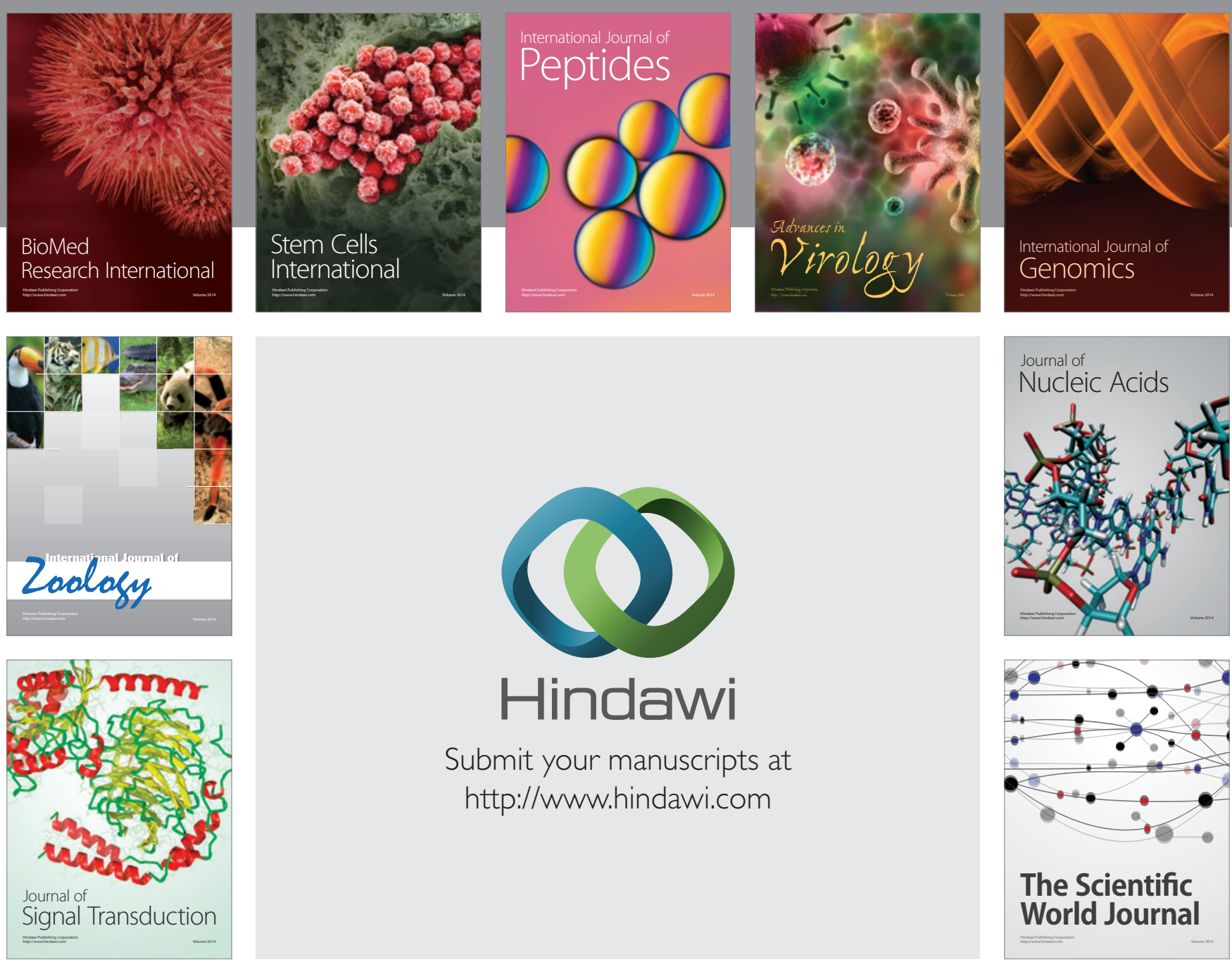

Submit your manuscripts at

http://www.hindawi.com
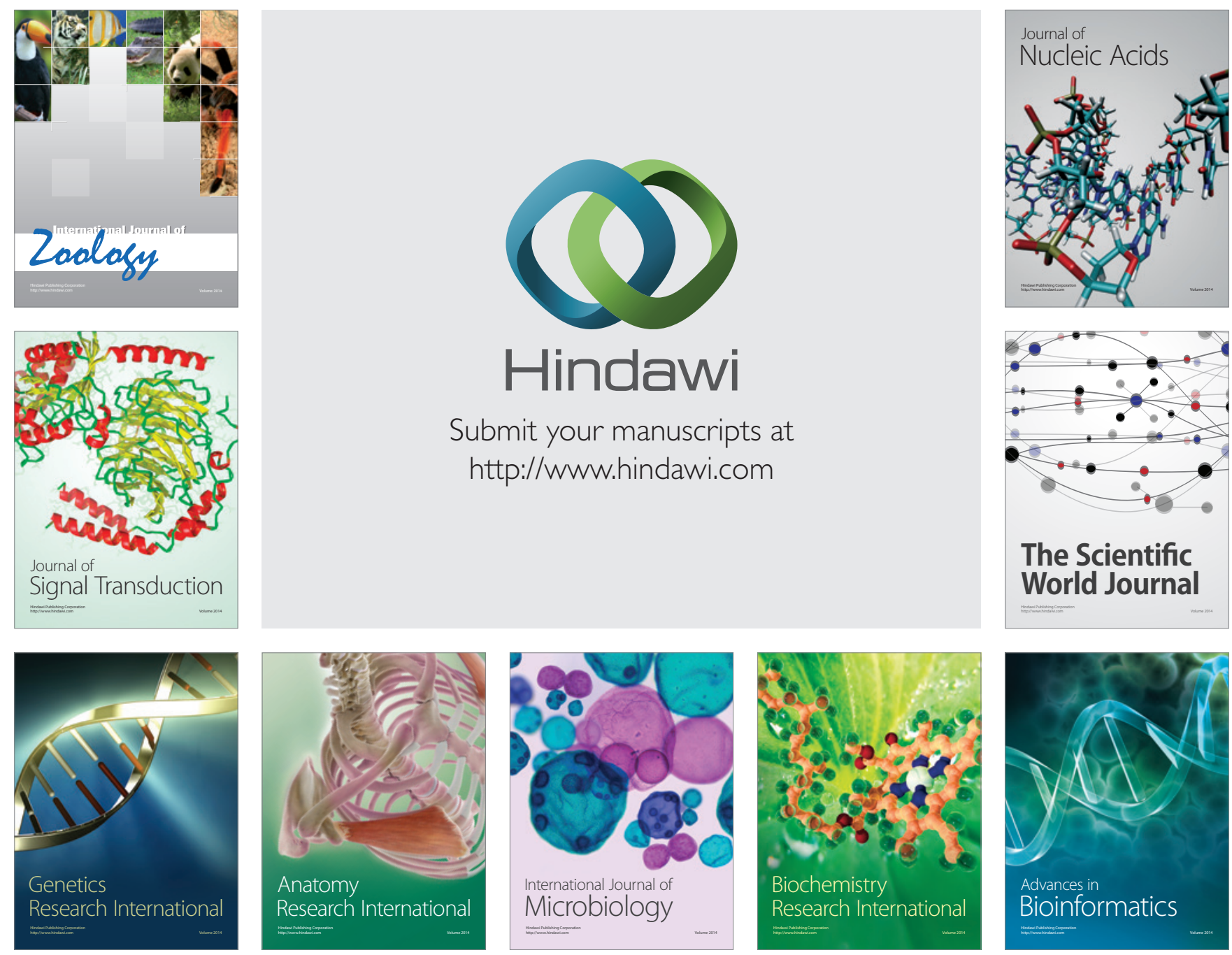

The Scientific World Journal
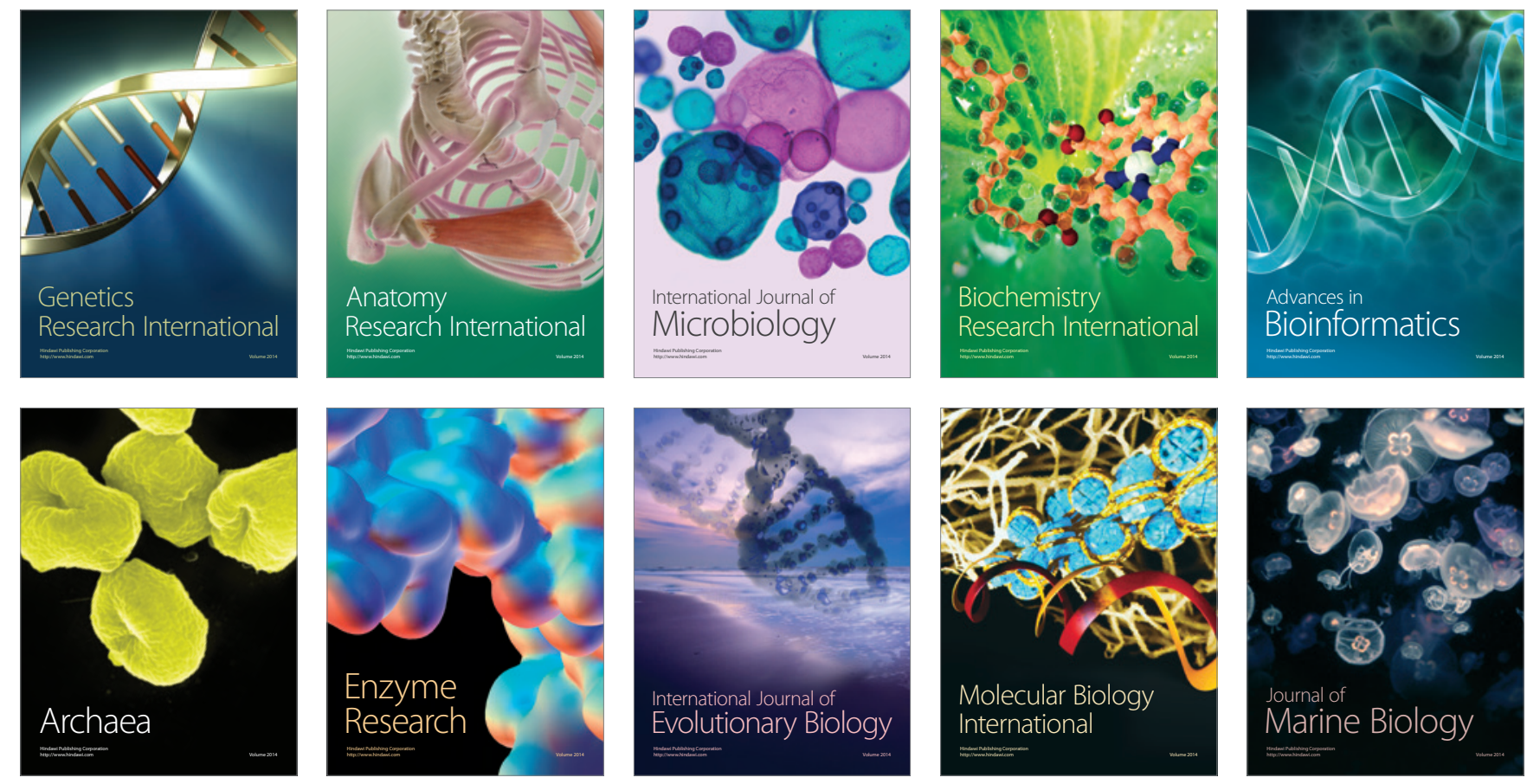